\title{
Management of hiccups in palliative care patients
}

\section{Yong Suk Jeon, ${ }^{1}$ Alison Mary Kearney, ${ }^{1,2}$ Peter Graham Baker ${ }^{3}$}

- Additional material is published online only. To view please visit the journal online (http://dx.doi.org/10.1136/ bmjspcare-2016-001264).

'School of Medicine, The University of Queensland, Brisbane, Queensland, Australia ${ }^{2}$ Department of Palliative and Supportive Care, Royal Brisbane and Women's Hospital, Brisbane, Queensland, Australia

${ }^{3}$ Discipline of General Practice, School of Medicine, The University of Queensland, Brisbane, Queensland, Australia

\section{Correspondence to} Dr Alison Mary Kearney, Department of Palliative and Supportive Care, Royal Brisbane and Women's Hospital, School of Medicine, The University of Queensland, Brisbane, QLD 4072, Australia;

Alison.Kearney@health.qld. gov.au

Received 21 October 2016 Revised 11 June 2017 Accepted 26 June 2017 Published Online First 13 July 2017
Check for updates

To cite: Jeon YS, Kearney AM, Baker PG. BMJ Supportive \& Palliative Care 2018;8:1-6.

\section{ABSTRACT}

Persistent hiccups are a frustrating experience for palliative care patients, and can have a profound impact on their quality of life. This article provides an evidence-based approach overview of the causes and treatment of this not infrequently debilitating condition for such patients, with a management algorithm. In situations where no readily reversible cause is identified, or where simple physical manoeuvres, such as breath holding have failed, a systematic approach is required. Hiccups can be broadly divided into central and peripheral types. These respond differently to pharmacological intervention. The drug of choice for central causes of persistent hiccups is baclofen, with metoclopramide recommended as the first choice for peripheral causes. Midazolam may be useful in cases of terminal illness. Interventional procedures such as vagal or phrenic nerve block or stimulation should be considered in patients who are refractory to medications. The management of persistent hiccups still presents an ongoing clinical challenge however, requiring further research on pathophysiology and treatment strategies. Multinational randomised controlled trials to evaluate and compare both current and new medications or procedures to better manage this difficult condition are suggested as a means of reaching this goal.

\section{INTRODUCTION}

A hiccup, also known as singultus, is an involuntary spastic contraction of the diaphragm and intercostal muscles that leads to inspiration of air, followed by abrupt closure of the vocal folds. The frequency and the duration can be variable in every patient. Hiccups can be classified based on duration: hiccup bouts (up to 48 hours); persistent hiccups (48 hours to 1 month); intractable hiccups (more than 1 month). ${ }^{1}$

Hiccups are very commonly experienced in any individual, and are usually self-limited. Hiccup bouts are thought to be caused by irritation of the stomach (overeating, rapid distension, spicy food, carbonated drinks or aerophagia), abrupt temperature change, alcohol, smoking or psychological causes such as sudden emotional change. ${ }^{12}$ Treatment of hiccups is necessary if they begin to cause inconvenience or distress. Persistent or intractable hiccups can adversely affect basic activities of daily living, including conversation, eating, drinking, sleep, mood, and can exacerbate pain. ${ }^{2} 3$ Through its constant interruptive nature hiccups can result in serious consequences, including malnutrition, weight loss, fatigue, dehydration, insomnia, psychological stress and decreased quality of life. ${ }^{1}$

The prevalence of hiccups is not well known, as most studies are based on case reports with small patient numbers. No racial, geographical or socioeconomic variations have been noted. In general, the prevalence of hiccups is thought to be higher in children, men and patients with comorbid conditions. ${ }^{2}$ Most hiccups are benign and self-limited, ceasing within hours. However, 1\%-9\% of patients with advanced cancer complain of persistent or intractable hiccups. ${ }^{3}$ A case report study on oesophageal cancer by Khorakiwala et al even suggested that hiccups should be considered as a potential presenting symptom of oesophageal cancer, as $27 \%$ of their 99 patients complained of persistent hiccups. ${ }^{4}$ Another study by Cleveland Medicine Program noted 9\% of their Palliative Medicine Program patients complained of hiccups. ${ }^{5}$ These data indicate that persistent and intractable hiccups can be extremely distressing and have a significant negative impact on quality of life for up to almost 1 in 10 palliative care patients.

This literature review aims to provide guidelines for the treatment of persistent or intractable hiccups in the palliative care setting. There are no clear guidelines for the treatment of persistent or intractable hiccups. A systematic review by Steger et 


\begin{tabular}{|c|c|}
\hline Level & Intervention \\
\hline । & A systematic review \\
\hline$\|$ & A randomised controlled trial \\
\hline |II-1 & $\begin{array}{l}\text { A pseudorandomised controlled trial (ie, alternate } \\
\text { allocation) }\end{array}$ \\
\hline |II-2 & A comparative study with concurrent controls \\
\hline ||l-3 & A comparative study without concurrent controls \\
\hline IV & Case series \\
\hline
\end{tabular}

$a l^{6}$ observed that choice of medication by physicians and specialists could be influenced by both causes and the specialty of the medical practitioner. ${ }^{6}$ Gastroenterologists, for example, tended to use baclofen, metoclopramide and neuroleptics, while neurologists favoured gabapentin and baclofen.

\section{METHODS}

PubMed searches (1950-2016) were performed with various $\mathrm{MeSH}$ term combinations, including but not limited to 'hiccup' and 'palliative care' or 'hospices' or 'terminal cancer'. A snowballing strategy was then employed to identify other associated articles through listed references. The last search was run on 30 September 2016. The exclusion criteria were persistent or intractable hiccups due to procedure or surgery. Initial review revealed no randomised controlled studies, but there were a number of case reports. The search was therefore expanded to include outcomes of non-palliative care patients in randomised controlled trials. The NHMRC (National Health and Medical Research Council) Evidence Hierarchy was used to designate levels of evidence according to research type (table 1$)^{7}$

\section{CAUSES OF HICCUPS}

The physiological mechanism of hiccups remains unclear. The hiccup 'reflex arch' with afferent limb, central mediator and efferent limb is thought to cause the condition. The medulla oblongata, reticular formation, hypothalamus and upper spinal cord (C3-C5) are considered to be involved. In the central nervous system, gamma-amino-butyric-acid and dopaminergic neurotransmitters are involved in modulating signals. The afferent limb is thought to involve the vagus, phrenic and sympathetic nerves, and the efferent limb mediated through the phrenic nerve to the diaphragm. ${ }^{68}$ The causes of hiccups may be divided into central and peripheral types, which can prove useful in guiding therapy; however, this is not evidence based.

The most common cause of hiccup is gastric reflux and distension. Peripheral causes can be divided into gastrointestinal and non-gastrointestinal. Gastrointestinal conditions include gastro-oesophageal reflux disease (GORD), hernia, malignancy, peptic ulcer disease and gastroparesis. These will often cause hiccup bouts in non-palliative patients but there is usually a requirement for additional management and monitoring in palliative patients. Non-gastrointestinal peripheral causes include myocardial infarction, pericarditis, aortic aneurysm, bronchitis, pneumonia, asthma, tuberculosis, rhinitis, otitis, pharyngitis and other opportunistic infections in immunocompromised patients. Peripheral causes are thought to cause hiccups by irritation of the phrenic or vagus nerve. Central causes can be divided into neurological such as cerebrovascular accident, brain trauma, intracranial tumour, multiple sclerosis, Parkinson's syndrome and non-neurological conditions (eg, infections). ${ }^{9}$

Other major causes include, but are not limited to, electrolyte imbalance (hyponatraemia, hypokalaemia, hypocalcaemia, hypocapnia, renal impairment), diabetes, alcohol, surgery related, psychogenic (anxiety, stress, fear) and medication. ${ }^{2}$ It should be noted that a number of drugs implicated as causes of hiccups are widely used in a palliative care setting. They include opioids, benzodiazepines, dexamethasone, dopamine agonists and chemotherapeutic agents. ${ }^{2}$ Some of these drugs are also used to treat intractable hiccups (table 2).

\section{TREATMENT OF HICCUPS}

Due to potential side effects of pharmacological agents, non-pharmacological physical manoeuvres should be performed before commencing pharmacological therapy. Commonly used non-pharmacological physical manoeuvres include interruption of the respiratory cycle (eg, holding breath, Valsalva manoeuvrecausing hypercapnia), irritation of the nasopharynx (ie, drinking water, manually pulling out tongue) or preventing diaphragm irritation (eg, leaning forward, pulling knees to chest). Anecdotal reports of acupuncture and complementary or alternative therapies have also been reported as potential treatments for intractable hiccups, although clear proof of efficacy is lacking. ${ }^{10}{ }^{11}$ On occasion, a patient may have devised their own individual method of stopping or reducing attacks, and this possibility should always be explored.

The treatment of hiccups should generally be guided by the nature of the underlying cause. However, given that this is likely to be multifactorial in palliative care situations, a symptomatic approach is often more applicable. ${ }^{3}$ There are a number of drugs that have been commonly used for chronic hiccups. Most of these medications act via dopaminergic or GABAergic pathways. These comprise chlorpromazine, haloperidol, benzodiazepines, gabapentin, metoclopramide and baclofen. Of these, chlorpromazine has previously been approved for this purpose by US Food and Drug Administration (FDA). However, significant side effects, particularly hypotension, urinary retention and delirium, have led to withdrawal of 
Table 2 Classification of persistent and intractable hiccups in palliative patients

\begin{tabular}{ll}
\hline Central type & Common conditions \\
\hline Neurological & Cerebrovascular accident, multiple sclerosis, parkinsonism, brain tumour \\
\hline Non-neurological & Infection, trauma \\
\hline Peripheral & Common conditions \\
\hline Gastrointestinal & $\begin{array}{l}\text { Distension, gastro-oesophageal reflux disease, gastritis, peptic ulcer disease, pancreatitis, gallbladder disease, hepatitis, } \\
\text { aerophagia, bowel obstruction, neoplasm }\end{array}$ \\
Non-gastrointestinal & $\begin{array}{l}\text { Thoracic (myocaridal infarction, pericarditis, aortic aneurysm, pneumonia, bronchitis, tuberculosis), neoplasm, rhinitis, otitis, } \\
\text { pharyngitis }\end{array}$ \\
\hline Other causes & Common examples \\
\hline Toxic metabolic & $\begin{array}{l}\text { Alcohol, diabetes, systemic infections (influenza, tuberculosis, malaria), hyponatraemia, hypokalaemia, hypocalcaemia, } \\
\text { hypocapnia, uraemia }\end{array}$ \\
Drugs & Opioids, diazepam, barbiturates, dexamethasone, alpha-methyldopa, dopamine agonist and chemotherapeutic agents \\
Psychogenic & Anorexia, anxiety, stress, schizophrenia \\
\hline
\end{tabular}

approval. Evidence for efficacy of chlorpromazine for hiccups dates back to case series from the 1950s. This, coupled with promising recent findings from literature reviews, randomised controlled trials and case reports, is shifting the trend towards other medications. ${ }^{2}$

The relative lack of research data concerning the pharmacological treatment of hiccups is due at least in part to the scarcity of patients. To date, there are no randomised controlled studies of pharmacological treatments of intractable hiccups in patients in palliative care settings. Three randomised controlled studies of pharmacological treatment of intractable hiccups in non-palliative patients were found in the literature (see online supplementary file 1). ${ }^{12-14}$ The first randomised controlled study was performed by Ramírez and Graham ${ }^{12}$ to evaluate baclofen as a potential treatment for four patients with intractable hiccups. The result showed that there was a statistically significant $(p=0.03)$ improvement of hiccups. ${ }^{12}$ The other two studies were published by the affiliated hospital of Harbin Medial University, China, in 2014, and showed improvement with baclofen and metoclopramide, respectively. ${ }^{1314}$

\section{Peripheral: gastrointestinal}

Hiccups secondary to GORD or other gastrointestinal cause were reported to be helped by proton pump inhibitors (eg, lansoprazole) and prokinetic agents (eg, metoclopramide). ${ }^{2} 31011$ 14-16 These are considered relatively safe with correct titration and close observation (see online supplementary appendix 3 ).

Proton pump inhibitors might improve hiccups by lowering acid secretion. A case report by Maximov and Kamnasaran showed significant improvement of hiccups with the use of lansoprazole, clonazepam and dimenhydrinate in a patient with gastritis, reflux esophagitis and recent myocardial infarction. ${ }^{17}$ This patient was not responsive to chlorpromazine, metoclopramide or baclofen.

Metoclopramide, a dopamine antagonist and prokinetic agent, was evaluated in several case reports and reviews. A case series of 14 patients with intractable hiccups from various causes also suggested that metoclopramide showed dramatic relief of hiccups in patients with gastrointestinal causes (ie, viral hepatitis with oesophagitis, haemorrhagic gastritis). ${ }^{1416}$

\section{Peripheral: non-gastrointestinal}

A literature search of treatment of hiccups due to peripheral causes produced a number of case reports concerning various pharmacological regimes, including baclofen, gabapentin, lidocaine, methylphenidate, midazolam and nimodipine (see online supplementary appendix 3). ${ }^{1418-32}$

The only relevant randomised controlled study for peripheral causes is Wang and Wang, ${ }^{14}$ where metoclopramide showed improvement with both central and peripheral causes of hiccups. A concern of longterm metoclopramide for non-palliative patients was raised due to extrapyramidal side effects. However, in patients with limited prognosis, the benefit of symptom control may outweigh the risk of possible adverse drug effects.

\section{Central}

There was a very limited number of studies involving persistent hiccups caused by central nervous system lesions (see online supplementary appendix 2). ${ }^{183-39}$ Some patients with intracranial malignancy were treated with surgical resection of the lesion, with other studies mostly related to the management of vascular lesions of the brainstem rather than palliative care situations.

A randomised controlled trial by Zhang et al ${ }^{13}$ compared baclofen, which is a $\mathrm{GABA}_{\mathrm{B}}$ (gamma-aminobutyric acid) receptor agonist $(10 \mathrm{mg}$ three times a day for 5 days), and placebo for the treatment of persistent hiccups in 30 patients with stroke. The result of this study showed that baclofen was more effective than placebo $(p=0.003){ }^{13}$ There were no significant adverse effects, other than one case of each mild transient drowsiness and dizziness. The efficacy 
of baclofen can be further supported by several case reports regarding chronic hiccups associated with underlying brainstem or spinal cord lesions.

Another randomised controlled trial by Wang and Wang ${ }^{14}$ compared metoclopramide (10 mg three times a day for 15 days) and placebo for the treatment of intractable hiccups in 36 patients. ${ }^{14}$ The underlying conditions of patients in this study were 17 patients with non-brain cancer, 14 patients with stroke and 5 patients with cerebral tumours. The results of this study showed that metoclopramide had higher efficacy than placebo $(p=0.03)$. However, it was noted that complete cessation of hiccups was achieved in only two patients with 'subjective' alleviation of the hiccups seen in nine patients.

The efficacy of gabapentin, which acts via alpha2delta-1 subunit of voltage-gated calcium channels, for hiccups of central type is not strongly supported by any randomised controlled trial. Nevertheless, there are several case reports and systematic reviews indicating that gabapentin can be a potential candidate for treatment of hiccups with a central aetiology. A systematic review by Steger $e t a l^{6}$ concluded that its effectiveness in peripheral types of conditions was limited. However, given that gabapentin is commonly useful in the palliative setting for neuropathic pain control, it may be beneficial to try gabapentin before other pharmacological regimes, such as chlorpromazine, haloperidol and nimodipine.

\section{Interventional approaches}

If non-pharmacological manoeuvres and pharmacological interventions are not successful, procedural or surgical interventions should be considered to control intractable hiccups. The risk versus benefits should be carefully explored and discussed with the patient and family members. These approaches may not always be appropriate for palliative patients when quality of life considerations are undertaken, but can be useful when of limited invasiveness. For example, a number of case reports showed that intractable hiccups, which were not manageable with pharmacological treatment, ceased after phrenic or vagal nerve blockage or stimulation (see online supplementary appendix 4). ${ }^{40-45}$ One case report from South Korea showed that positive pressure ventilation could be a potential management for idiopathic hiccups where both pharmacological and procedural approaches had failed.

A systematic review and meta-analysis of acupuncture treatment for patients suffering from intractable hiccups suggested some benefit when used as an adjunct to medical therapy. ${ }^{46}$ However, a number of researchers have indicated that definitive conclusions and strong evidence of efficacy was not obtainable due to the limited number of randomised controlled studies and poor methodologies.
Palliative patients with recurrent episodes of hiccups causing distress and unresponsive to physical manoeuvres (e.g. breath holding)

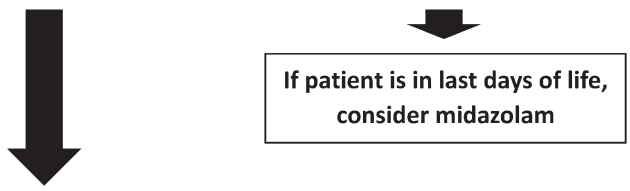

\begin{tabular}{|c|c|c|c|}
\hline \multicolumn{4}{|c|}{$\begin{array}{l}\text { Explore potential underlying causes with history taking, physical } \\
\text { examination and clinical review. Review and address potential causes } \\
\text { if feasible: drugs (e.g. opioids, benzodiazepines, dexamethasone), } \\
\text { toxic/metabolic (e.g. alcohol, uraemia, electrolyte imbalance), } \\
\text { psychogenic (e.g. anxiety, anorexia) }\end{array}$} \\
\hline \multicolumn{4}{|c|}{ If no cause found, consider PPI } \\
\hline & First line & Second line & Alternatives \\
\hline $\begin{array}{l}\text { Peripheral } \\
\text { (gastric) }\end{array}$ & $\begin{array}{l}\text { Metoclopramide } \\
\text { (level II) or Proton } \\
\text { pump inhibitor } \\
\text { (when suspecting } \\
\text { reflux) }\end{array}$ & \multirow[t]{2}{*}{$\begin{array}{l}\text { Baclofen or } \\
\text { Gabapentin (level } \\
\text { IV) }\end{array}$} & \multirow{2}{*}{$\begin{array}{l}\text { Chlorpromazine, } \\
\text { Midazolam, } \\
\text { Nimodipine, } \\
\text { Olanzapine } \\
\text { Lidocaine or } \\
\text { Methylphenidate } \\
\text { (level IV) }\end{array}$} \\
\hline $\begin{array}{l}\text { Peripheral } \\
\text { (non-gastric) }\end{array}$ & $\begin{array}{l}\text { Metoclopramide } \\
\text { (level II) }\end{array}$ & & \\
\hline Central & Baclofen (level II) & $\begin{array}{l}\text { Gabapentin (level } \\
\text { IV) }\end{array}$ & $\begin{array}{l}\text { Haloperidol or } \\
\text { Nimodipine (level } \\
\text { IV) }\end{array}$ \\
\hline \multicolumn{4}{|c|}{ If no response, consider procedural intervention } \\
\hline
\end{tabular}

Figure 1 Treatment algorithm for persistent and intractable hiccups in palliative care patients. PPI, proton pump inhibitor.

\section{PROPOSED TREATMENT ALGORITHM}

Using the NHMRC Evidence Hierarchy, a treatment algorithm for intractable hiccups in palliative care patients has been developed (figure 1). If no clear cause is found, consider the empirical use of a proton pump inhibitor due to gastric reflux being the most common cause of hiccups.

If intractable hiccups are caused by a central type of condition, baclofen (level II) is recommended as firstline treatment. It is the only drug that was supported by randomised controlled trials. Based on evidence from case reports, second-line agents include gabapentin, haloperidol and nimodipine (level IV).

For hiccups due to peripheral causes, metoclopramide (level II) is recommended as the first-line treatment. It was the only drug whose efficacy was supported by randomised controlled trials. Proton pump inhibitors may be useful where hiccups are clearly related to gastroreflux symptoms. Second-line agents for peripheral types of hiccups include baclofen, gabapentin, olanzapine, lidocaine methylphenidate, midazolam and nimodipine (level IV).

If a patient is in the last few days of life, consideration should be given to using midazolam by subcutaneous infusion to relieve intractable hiccups. Midazolam may also be used while trialling the efficacy of other treatments. Midazolam is commonly used in the terminal 


\begin{tabular}{ll}
\hline Table 3 & Summary of medication dosages \\
\hline Medication(s) & Dosage \\
\hline Baclofen & $5-15 \mathrm{mg}$ three times a day \\
Metoclopramide & $10 \mathrm{mg}$ three times a day \\
Gabapentin & $100-400 \mathrm{mg}$ three times a day \\
Midazolam & $10-60 \mathrm{mg} / 24$ hours SC \\
\hline Haloperidol & $1-4 \mathrm{mg} / 24$ hours SC/oral/intramuscular \\
\hline Omeprazole & $20 \mathrm{mg}$ twice a day \\
Chlorpromazine & $10-50 \mathrm{mg}$ three times a day intravenous/ \\
& oral \\
\hline
\end{tabular}

SC, subcutaneous.

phase of patient care-for management of agitation and distress. This general sedation effect was also found to be useful to suppress hiccup reflexes through case reports. ${ }^{3031}$ Refer to table 3 for dosing guideline recommendations.

\section{CONCLUSION}

Persistent or intractable hiccups remain a diagnostic and therapeutic challenge, and can affect a significant minority of palliative care patients. Chlorpromazine, in use for 65 years, remains the only medication with US FDA approval to treat this debilitating condition, but adverse side effects can restrict its use. Limited research findings have more recently established the benefit of newer agents. These include baclofen for hiccups of predominantly central type, and metoclopramide or proton pump inhibitors for patients with peripheral causes.

Further studies of persistent hiccups would increase the understanding of this condition but will require significant collaboration due to the rarity of cases. Future research could involve randomised controlled trials comparing baclofen, metoclopramide and gabapentin in the management of hiccups.

Contributors Conception or design of the work: AMK. Data collection: YSJ. Data analysis and interpretation: YSJ. Drafting the article: YSJ. Critical revision of the article: AMK, PGB. Final approval of the version to be published: YSJ, AMK, PGB.

Competing interests None declared.

Ethics approval This article does not contain any studies with human or animal subjects performed by any of the authors. No study approval was obtained.

Provenance and peer review Not commissioned; externally peer reviewed.

(C) Article author(s) (or their employer(s) unless otherwise stated in the text of the article) 2018. All rights reserved. No commercial use is permitted unless otherwise expressly granted.

\section{REFERENCES}

1 Kolodzik PW, Eilers MA. Hiccups (singultus): review and approach to management. Ann Emerg Med 1991;20:565-73.

2 Woelk CJ. Managing hiccups. Can Fam Physician 2011;57:672e198-201.
3 Calsina-Berna A, García-Gómez G, González-Barboteo J, et al. Treatment of chronic hiccups in cancer patients: a systematic review. J Palliat Med 2012;15:1142-50.

4 Khorakiwala T, Arain R, Mulsow J, et al. Hiccups: an unrecognized symptom of esophageal cancer? Am J Gastroenterol 2008;103:801.

5 Walsh D, Donnelly S, Rybicki L. The symptoms of advanced cancer: relationship to age, gender, and performance status in 1,000 patients. Support Care Cancer 2000;8:175-9.

6 Steger M, Schneemann M, Fox M. Systemic review: the pathogenesis and pharmacological treatment of hiccups. Aliment Pharmacol Ther 2015;42:1037-50.

7 Coleman K, Norris S, Weston A, et al. NHMRC additional levels of evidence and grades for recommendations for developers of guidelines. Canberra: NHMRC, 2005.

8 Samuels L. Hiccup; a ten year review of anatomy, etiology, and treatment. Can Med Assoc J 1952;67:315-22.

9 Kobayashi Z, Tsuchiya K, Uchihara T, et al. Intractable hiccup caused by medulla oblongata lesions: a study of an autopsy patient with possible neuromyelitis optica. J Neurol Sci 2009;285:241-5.

10 Moretto EN, Wee B, Wiffen PJ, et al. Interventions for treating persistent and intractable hiccups in adults. Cochrane Database Syst Rev 2013;1:CD008768.

11 Smith HS, Busracamwongs A. Management of hiccups in the palliative care population. Am J Hosp Palliat Care 2003;20:149-54.

12 Ramírez FC, Graham DY. Treatment of intractable hiccup with baclofen: results of a double-blind randomized, controlled, cross-over study. Am J Gastroenterol 1992;87:1789-91.

13 Zhang C, Zhang R, Zhang S, et al. Baclofen for stroke patients with persistent hiccups: a randomized, double-blind, placebocontrolled trial. Trials 2014;15:295.

14 Wang T, Wang D. Metoclopramide for patients with intractable hiccups: a multicentre, randomised, controlled pilot study. Intern Med J 2014;44:1205-9.

15 Chang FY, Lu CL. Hiccup: mystery, nature and treatment. J Neurogastroenterol Motil 2012;18:123-30.

16 Madanagopolan N. Metoclopramide in hiccup. Curr Med Res Opin 1975;3:371-4.

17 Maximov G, Kamnasaran D. The adjuvant use of lansoprazole, clonazepam and dimenhydrinate for treating intractable hiccups in a patient with gastritis and reflux esophagitis complicated with myocardial infarction: a case report. BMC Res Notes 2013;6:327.

18 Hernández JL, Fernández-Miera MF, Sampedro I, et al. Nimodipine treatment for intractable hiccups. Am J Med 1999;106:600.

19 Friedgood CE, RIPSTEIN CB. Chlorpromazine (thorazine) in the treatment of intractable hiccups. J Am Med Assoc 1955;157:309-10.

20 Wilcox SK, Garry A, Johnson MJ. Novel use of amantadine: to treat hiccups. J Pain Symptom Manage 2009;38:460-5.

21 Turkyilmaz A, Eroglu A. Use of baclofen in the treatment of esophageal stent-related hiccups. Ann Thorac Surg 2008;85:328-30.

22 Walker P, Watanabe S, Bruera E. Baclofen, a treatment for chronic hiccup. J Pain Symptom Manage 1998;16:125-32.

23 Hernández JL, Pajarón M, García-Regata O, et al. Gabapentin for intractable hiccup. Am J Med 2004;117:279-81.

24 Rizzo C, Vitale C, Montagnini M. Management of intractable hiccups: an illustrative case and review. Am J Hosp Palliat Care 2014;31:220-4.

25 Menon M. Gabapentin in the treatment of persistent hiccups in advanced malignancy. Indian J Palliat Care 2012;18:138-40.

26 Porzio G, Aielli F, Verna L, et al. Gabapentin in the treatment of hiccups in patients with advanced cancer: a 5-year experience. Clin Neuropharmacol 2010;33:179-80. 
27 Kaneishi K, Kawabata M. Continuous subcutaneous infusion of lidocaine for persistent hiccup in advanced cancer. Palliat Med 2013;27:284-5.

28 Neuhaus T, Ko YD, Stier S. Successful treatment of intractable hiccups by oral application of lidocaine. Support Care Cancer 2012;20:3009-11.

29 Maréchal R, Berghmans T, Sculier P. Successful treatment of intractable hiccup with methylphenidate in a lung cancer patient. Support Care Cancer 2003;11:126-8.

30 Wilcock A, Twycross R. Midazolam for intractable hiccup. J Pain Symptom Manage 1996;12:59-61.

31 Moro C, Sironi P, Berardi E, et al. Midazolam for long-term treatment of intractable hiccup. J Pain Symptom Manage 2005;29:222-3.

32 Koçkar C, İşler M, Cüre E, et al. Two cases of hiccups due to gastroesophageal reflux disease. European Journal of General Medicine 2009;6.

33 Baumann A, Weicker T, Alb I, et al. Baclofen for the treatment of hiccup related to brainstem compression. Ann Fr Anesth Reanim 2014;33:e27-e28.

34 Boz C, Velioglu S, Bulbul I, et al. Baclofen is effective in intractable hiccups induced by brainstem lesions. Neurol Sci 2001;22:409.

35 Fodstad H, Nilsson S. Intractable singultus: a diagnostic and therapeutic challenge. Br J Neurosurg 1993;7:255-60.

36 Moretti R, Torre P, Antonello RM, et al. Treatment of chronic: new perspectives. Eur J Neurol 1999;6:617.

37 Moretti R, Torre P, Antonello RM, et al. Gabapentin as a drug therapy of intractable hiccup because of vascular lesion: a three-year follow up. Neurologist 2004;10:102-6.
38 Carlisi E, Bossi D, Zaliani A, et al. Persistent hiccup after surgical resection of a brainstem arteriovenous malformation: a case successfully treated with gabapentin during rehabilitation. Case report. Eur J Phys Rehabil Med 2012;48:289-91.

39 Ives TJ, Fleming MF, Weart CW, et al. Treatment of intractable hiccups with intramuscular haloperidol. Am J Psychiatry $1985 ; 142: 1368-9$.

40 Arsanious D, Khoury S, Martinez E, et al. UltrasoundGuided phrenic nerve block for intractable hiccups following Placement of Esophageal Stent for Esophageal Squamous Cell Carcinoma. Pain Physician 2016;19:E653-6.

41 Sa YJ, Song DH, Kim JJ, et al. Recurrent intractable hiccups treated by cervical phrenic nerve block under electromyography: report of a case. Surg Today 2015;45:1446-9.

42 Kim JJ, Sa YJ, Cho DG, et al. Intractable hiccup accompanying pleural effusion: reversible clipping of an intrathoracic phrenic nerve. Surg Laparosc Endosc Percutan Tech 2013;23:357-9.

43 Byun SH, Jeon YH. Treatment of idiopathic persistent hiccups with positive pressure ventilation -a case report-. Korean J Pain 2012;25:105-7.

44 Schulz-Stübner S, Kehl F. Treatment of persistent hiccups with transcutaneous phrenic and vagal nerve stimulation. Intensive Care Med 2011;37:1048-9.

45 Payne BR, Tiel RL, Payne MS, et al. Vagus nerve stimulation for chronic intractable hiccups. Case report. J Neurosurg 2005;102:935-7.

46 Yue J, Liu M, Li J, et al. Acupuncture for the treatment of hiccups following stroke: a systematic review and metaanalysis. Acupunct Med 2017;35:2-8. 